100

\title{
Internationalising Media Production: Early Users of Remote Creative Collaboration Tools
}

\author{
Ellen Baker, John Geirland*, Annmarie Chandler, Tom Fisher, Rachel Moss \\ University of Technology, Sydney \\ PO Box 123 Broadway 2007 (Australia) \\ * Center for Executive Learning, Loyola Marymount University (USA) \\ E.Baker\{A.Chandler, T.Fisher\}@uts.edu.au Geirland@aol.com
}

\begin{abstract}
During 1996 there was a shap increase in the use of remote collaboration technologies within the advertising and film industries. There was even some intenational collaboration, driven by the need to use scarce expertise located elsewhere. This paper reports on a series of case studies carried out in Australia, the U.S. and the U.K. to assess the reactions of these forefont users and to try to determine 1) which CSCW tools will be most usefil for international production applications and 2) what conditions will facilitate creative collaboration internationally.
\end{abstract}

KEYWORDS CSCW, Multimedia, Art and Media, New or Emerging Technologies, Management Issues.

\section{INTRODUCTION AND METHOD}

Global working encounters many diffculties (O'HaraDevereaux \& Johansen, 1994) and international collaboration on creative products presents additional challenges, because their failure rate is high and media production is costly. Anxiety levels are high and staf tend to be chosen on the basis of long-term relationships nurtured during previous projects. Media production is generally divided into three segments (pre-production, production, post-production) and remote collaboration may be needed within any of these stages. Creative staf generally carry out assigned work independently and then submit it periodically for approval.

Semi-structured interviews were conducted in seven organisations in L.A., London and Sydney that recently used remote international collaboration for motion-video production. Further information was obtained from two wide-area-network consortia, Sohonet in London and Hollynet in L.A. Most of the companies were in postproduction, one was a major U.S. studio. Two of the companies have offices in both L.A. and London.

\section{COLLABORATION TECHNOLOGIES}

These early users confrm that close collaboration is possible in media production work internationally, even with the support tools available in 1996. Tools currently used fall into three categories.

1) Electronic Delivery is used instead of couriers, to get quicker decisions or approvals, or to transfer computer image files for additional processing, such as effects work. Some systems (e.g. the Videofax) have been specifically designed for media industry applications.

2) Interactive access or control extends the reach of the creative person beyond their own workstation. Some companies have high speed internal networks connecting all their equipment and these networks are now being extended intemationally. Nominated files are accessed, modified and then returned to the host computer by the collaborators, which corresponds to the CSCW category 'diferent time, same plaœ'.

3) Synchronous collaboration systems support personto-person, realtime collaboration on visual material, the $\mathrm{CSCW}$ category 'same time, different place'. The most

Human-Computer Interaction: INTERACT'97 S. Howard, J. Hammond \& G. Lindgaard (editors)

Published by Chapman \& Hall CIFIP 1997 
commonly used form is a combination of the telephone with some techology for simultaneously viewing a fame or film clip. Generally this uses only priar electronic delivery but a number of systems, specifically designed for media production work, with shared workspaces, are now available (e.g Sprint Drums). The sofware supports scrolling and annotating of motion video in a shared workspace and has a small video-conferencing window for a view of users' faces.

One of our case study companies felt that the information participants would receive about each other on a workstation would be too limited so instead they began with a room-based videoconferencing system and then integrated other functionality on an 'as needed' basis. They use this system regularly between L.A. and London.

\section{FACILITATING INTERNATIONAL COLLABORATION}

Our case studies point to a number of propositions.

1) Asynchronous vs synchronous - Real-time collaboration will be needed but most communication will be asynchronous, due to time zone differences and the advantage of a quidk response over scheduling a meeting. Collaborators will capitalise on timezone differences, to maximise the effective working time at each location or to allow work to go on around the clodk.

2) Coordination needs - Extensive coordination will be an important need, as is illustrated by one case study. Animation work for a film was being done in L.A. and London simultaneously and integration of these activities required continual use of auxillary support facilities, such as electronic mail.

3) Increased creative control - User acceptance of International collaboration will offen depend on whether it results in increased creative control for the film/TV director or advertising/studio exeautive. Interviewees reparted greater involvement in the details of productions by these people, even if they were in another country at the time

4) Security - Curnent security conœrns about the use of computer networks for media collaboration will decrease, along with current conœrns about credit card information over the Internet.

5) Trust, stress reduction, improved work practices Remote collaboration will require trust between media coworkers. Although there are strong bonds from similarity of norms within the worldwide media production community, pria in-person collaboration will still probably be necessary. Use of CSCW tools will result in creative production staf having shorter waiting times for feedack and everyone feling more confdent that the desired product will emerge at the end. Work practices will also be normalised and become more efficient, with less shif work and fewer very long workdays.

6) Videoconferencing - Media production provides a good example of what Whittaker (1995) called 'video as datd, and also may provide support for what he called the 'social cueing hypothesis', that visual information provides cues about emotion. Our interviewees (both those who use videoconferencing and those who don't) emphasised the importance of seeing the people you are collaborating with Although people generally overestimate the usefilness of seeing the people they are communicating with in this relaionship-dominated industry seeing faces may be more valuable, and specially designed support systems may facilitate collaboration.

Overall, the successes reparted by the early users studied indicate that, although there are challenges ahead, this is the future direction of media production.

We thank the companies that participated for their permission to publish these results, and the Australian Research Council (Grant A79530730), the Australian Film TV \& Radio School and the Faculty of Business, UTS.

\section{REFERENCES}

O'Hara-Devereaux, M. \& Johansen, R. (1994) Global Work Jossey-Bass, San Francisco.

Whittaker, S. (1995) Rethinking Video as Technology for Interpersonal Communications. International Joumal of Human-Computer Studies, 42, 501-529. 